\title{
Política, religión y revolución en la obra inicial sobre el Perú de Jeffrey Klaiber S. J.
}

\section{Politics, religion and revolution in Jeffrey Klaiber S. J.'s early work on Peru}

Ricardo Felipe Portocarrero Grados ${ }^{1}$

Archivo José Carlos Mariátegui

\section{Resumen}

El objetivo del artículo es estudiar el contexto histórico y el proceso político e intelectual de los primeros trabajos de investigación realizados por el historiador norteamericano Jeffrey Klaiber S. J. En ellos, se enfocó en estudiar las posibilidades de un cambio profundo en el Perú por medio de políticas reformistas, que encontraban en el Partido Aprista Peruano su principal actor político. Además, estudió las relaciones entre las élites reformistas y los sectores populares a lo largo de nuestra historia republicana, cuyo principal resultado fue su importante libro Religión y Revolución en el Perú, 1824-1988.

Palabras clave: política, religión, revolución, Perú, siglo XX

\section{Abstract}

The objective of this article is to study the historical context and the political and intellectual process of the first research works

1 Licenciado en Historia por la Pontificia Universidad Católica del Perú, Máster en Historia de América Latina Contemporánea del Colegio de América de Sevilla y con estudios de doctorado por el Instituto Universitario Ortega y Gasset de Madrid. Código ORCID: 0000-0002-9295- 8050. Contacto: portos10@hotmail.com. 
carried out by the North American historian Jeffrey Klaiber S. J. In his works, he focused on the possibilities of a profound change in Peru through reformist policies, which found in the Peruvian Aprista Party its main political actor. In addition, he studied the relationships between the reformist elites and the popular sectors throughout our republican history, the main result of which was his important book Religion and Revolution in Peru, 1824-1988.

Keywords: politics, religion, revolution, Peru, 20th century

\section{Introducción}

El presente texto busca rendir homenaje a uno de los historiadores que más influyeron en mi formación académica en mis años de estudios en la Pontificia Universidad Católica del Perú (PUCP) en la década de 1980. En esos años, en la especialidad de Historia todavía predominaban como centro de interés de la enseñanza y la investigación dos grandes temas: la etnohistoria y los primeros siglos coloniales. Los temas referidos al siglo XVIII y al siglo XIX recién comenzaban a cobrar interés entre los jóvenes investigadores. Mientras tanto, el estudio de las primeras décadas del siglo XX, que era el tema de mi interés, todavía tendría que esperar su hora. Ese período era el límite que la historiografía tradicional establecía entre la historia y la sociología o la política. El único profesor que fomentaba el interés y la investigación de dicho

80 siglo era Jeffrey Klaiber. Esta es la razón que me motivaría a conocer y estudiar sus trabajos históricos con el fin de contrastarlos con mis propios intereses.

En este sentido, presento, desde la perspectiva de la historia intelectual, los primeros trabajos de investigación de Jeffrey Klaiber sobre la historia del Perú republicano, en los que hace un balance del papel de los principales actores políticos 
y sociales, y de las relaciones entre estos, como una forma de entender la situación que el Perú vivía entonces. La principal hipótesis es que Klaiber encontraría en el Partido Aprista Peruano, el partido político más influyente del siglo XX, al actor político que explicaba las profundas transformaciones que el Perú atravesaba en esa época.

Para fundamentar dicha hipótesis, se ha dividido el texto en tres partes y un colofón. En la primera, se explica el proceso intelectual y político de inserción de Jeffrey Klaiber en la sociedad peruana, y su influencia en sus primeros trabajos de investigación histórica. En la segunda parte, se estudia el proceso de elaboración de su libro Religión y revolución en el Perú, alrededor del cual giran otros trabajos, que sentará las bases de su interpretación de la historia del Perú. En la tercera parte, a partir de la publicación de una nueva edición de Religión y revolución en el Perú se analiza su interpretación acerca de la situación del Perú en la década de 1980. Finalmente, en un breve colofón, se revisa cómo a principios del siglo XXI Klaiber persistía con optimismo en sus apuestas juveniles, pese a los profundos cambios que había sufrido el Perú a lo largo de la década de 1990.

\section{Jeffrey Klaiber y el Perú de su juventud}

Hace cinco años, por sugerencia de Nicanor Domínguez, escribí un obituario del padre Jeffrey Klaiber S. J. En él comenzaba haciendo una pregunta que no llegué a responder. Decía: "Un primer problema para hablar de él es cómo clasificarlo desde el punto de vista historiográfico: ¿fue un peruanista?" (Portocarrero Grados, 2015, p. 135). Creo que hoy en día, debido a la creciente globalización, esta pregunta ya no es válida. Su compromiso y amor por el Perú lo alejaba de cualquier afán clasificatorio nacionalista. Como historiador y como ser humano pertenecía al Perú. Nació el 11 de enero de 1943 en la ciudad de Indianápolis, Estados Unidos. A los 20 años llegó por primera vez a Lima, como novicio de la 
Compañía de Jesús, y desde 1976, con 33 años, residió de manera permanente en el Perú.

Si Klaiber hubiese nacido en el Perú, habría pertenecido en términos historiográficos, sin duda alguna, a la denominada generación del 68. Pero con una diferencia sustancial: su obra no estuvo influenciada por el marxismo. Habría mantenido, sin embargo, otros elementos comunes a los miembros de esta generación: su compromiso social con los sectores populares, una obra intelectual que orientó su quehacer eclesial y cotidiano, y la formación de más de una generación de jóvenes historiadores que compartían sus ideales.

Como ser humano, también compartió con esta generación - y con el resto de peruanos - el contexto histórico y social de la década de 1960, que influenció su proceso de formación personal e intelectual, y marcó los temas de sus investigaciones históricas, y su quehacer eclesial en el Perú. Entre los hechos internacionales relevantes caben destacar aquellos que llevaron al giro político e ideológico más importante de la Iglesia Católica desde el Concilio de Trento (1545-1563): el Concilio Vaticano II (Roma, 1962-1965) y la Segunda Conferencia de Obispos Latinoamericanos en Medellín, Colombia, en setiembre de 1968, que renovaron la doctrina y la práctica misional de la Iglesia.

En plena Guerra Fría (1947-1990), la Iglesia católica en América Latina no solo enfrentaba ideológicamente al comunismo, sino que sufría también las consecuencias de su fiel defensa del orden político y social en tanto fuerza cohesiva de la sociedad. Esto la ponía, en la mayoría de los casos, del lado de dictaduras militares o de oligarquías que gobernaban a costa de la desigualdad y la pobreza de la mayoría de la población, sobre todo indígena. La Iglesia se encontraba, pues, inmersa en una severa crisis de legitimidad. El giro político e ideológico se hacía necesario para hacer frente al reto que significaba el creciente número de movimientos revolucio- 
narios a nivel mundial, hayan sido de carácter nacionalista, socialista o anticolonial, dentro del cual el marxismo tenía un papel relevante. Y que a nivel latinoamericano se expresaba en la creciente influencia de la revolución cubana (1959) en los distintos países de América Latina. América Latina era entonces, según el historiador marxista británico Eric Hobsbawm, la que contaba con mayores posibilidades revolucionarias (Hobsbawm, 2018, p. 53).

En 1961, año en el que Klaiber entró a la orden jesuita, el papa Juan XXIII pidió a las órdenes religiosas y al clero diocesano de Estados Unidos, Canadá y Europa que enviasen el diez por ciento de sus miembros a América Latina. La razón era clara: el continente concentraba la mayor población católica del planeta y, sin embargo, históricamente enfrentaba una severa escasez de sacerdotes.

En cuanto al Perú, esos años estuvieron enmarcados dentro de la gestión eclesial de Juan Landázuri Ricketts como arzobispo de Lima y primado del Perú (1954-1990), cuando la Iglesia Católica peruana se orientó hacia un quehacer más comprometido con los sectores populares a través de importantes instituciones, como la Unión Nacional de Estudiantes Católicos (UNEC) y Caritas. Con su nombramiento como cardenal, Landázuri participó tanto en el Concilio Vaticano II como en la II Conferencia del Episcopado Latinoamericano en Medellín, donde se planteó por primera vez la “opción preferencial por los pobres". Este contexto explica la publicación del libro del padre Gustavo Gutiérrez, Teología de la liberación (1971), de gran influencia no solo en el Perú, sino también en América Latina. En ese sentido, a su llegada al Perú, Klaiber encontró en las comunidades de base católicas un campo fértil para el papel renovador, la sensibilidad social y el compromiso con el pobre, propio de esos ańos.

En cuanto al contexto político, Jeffrey Klaiber llegó en 1963 a un Perú oligárquico que empezaba a resquebrajarse, con 
masivas movilizaciones campesinas y tomas de tierras, grupos guerrilleros "foquistas", militares que reprimían a los izquierdistas radicales y monitoreaban las elecciones, y antiguos y nuevos partidos reformistas que competían por la presidencia. Ese Perú llegará a su fin como consecuencia del golpe militar encabezado por el general Juan Velasco Alvarado, el 3 de octubre de 1968, que con un discurso modernizador populista impulsó importantes reformas estructurales que pusieron fin al régimen oligárquico, imperante hasta entonces, y que Klaiber había llegado a vislumbrar.

Generalmente, los sacerdotes extranjeros se establecían en pequeñas parroquias en las zonas urbano-marginales o en los barrios de clase media en expansión. Además, específicamente los sacerdotes provenientes de la Compañía de Jesús tenían una tradicional presencia e influencia en el sistema educativo. Sin embargo, para los extremos políticos locales, la llegada masiva de sacerdotes norteamericanos llegó a ser vista como una "ofensiva imperialista" para unos y como una "invasión de curas rojos" para otros. No es de extrañar, entonces, que en los años de endurecimiento y de mayor represión política del régimen de Velasco, se haya visto obligado, como otros sacerdotes "rojos" de la época (norteamericanos, sobre todo) a huir hacia la frontera boliviana para evitar ir a prisión.

En la década de los ochenta, la denominada "década perdida", le tocó vivir como al resto de los peruanos una situación que combinaba una gravísima crisis económica y un conflicto armado interno. Las perspectivas más pesimistas vislumbraban la ruptura de nuestro todavía Estado nación en formación. Esa situación lo acercó a la generación de historiadores peruanos del 68, y su compromiso con el país lo llevó a estudiar temas espinosos de nuestra historia y de nuestro presente, que muchos consideraban subversivo.

En ese sentido, es pertinente hablar del grupo de trabajo interdisciplinario que organizó en la PUCP para estudiar la 
violencia política que azotaba al país. Aunque su interpretación se basaba en una perspectiva católica institucional que sostenía que el problema de la violencia política era expresión de una crisis de valores, convocó a un amplio grupo de especialistas con posturas diversas para trabajar el tema. El resultado de este trabajo fue el libro Violencia y crisis de valores en el Perú: trabajo interdisciplinario (Klaiber, 1987).

Cabe resaltar que hasta ese entonces la violencia política era un tema circunscrito a los intelectuales de izquierda: Nelson Manrique, Gonzalo Portocarrero, Rolando Ames, Carlos Iván Degregori, Alberto Flores Galindo, Sinesio López. Esta actitud contrasta con la postura oficial de la Iglesia Católica, pero en concordancia con una iglesia popular expresada en comunidades de base en departamentos como Ayacucho, Cusco, Puno y en los barrios urbano marginales de la capital.

Este vínculo se expresará en el hecho de que la totalidad de sus trabajos y la mayoría de cursos que dictó, incluso en los Estados Unidos (donde fue profesor visitante en la Georgetown University en 1990-1991, y en la Saint Joseph's University en 2000-2001), se refieren a la historia del Perú y de América Latina. No escribió sobre su país de nacimiento, aunque por muchos años dictó un curso titulado Historia de Estados Unidos, con el fin de introducir la historia y la cultura norteamericanas a un público peruano que, en algunos casos, podía tener una relación antagónica con ese país.

\section{Religión y revolución en el Perú}

Entre 1963, cuando llegó al Perú por primera vez, y 1976, cuando se estableció permanentemente en el país, el padre Klaiber realizó viajes intermitentes entre los Estados Unidos y el Perú. Durante esos años combinó su labor pastoral, su trabajo como profesor en el Colegio San José de Lima y sus estudios de formación académica en la Universidad de Loyola (Chicago) y en la Universidad Católica de América 
(Washington, D. C.). Su primera impresión del país fue encontrar la íntima relación que existía entre la política y la religión, sobre todo en el caso del Partido Aprista Peruano (PAP) liderado por Víctor Raúl Haya de la Torre. Según el testimonio de Klaiber:

Como sacerdote jesuita, he estudiado y trabajado en el Perú, en diferentes ocasiones desde 1963, y he tenido la oportunidad de observar el entrecruzamiento íntimo, y a veces sutil, de la política con la religión. En 1967 comencé a estudiar los orígenes universitarios del Partido Aprista y me llamó la atención el hecho de que el viejo anticlericalismo liberal y el catolicismo tradicional se habían mezclado en aquel movimiento tempestuoso y controvertido (1980, p. 12).

Este fue el tema que guio sus primeras investigaciones académicas sobre el Perú. No es arriesgado señalar que esa impresión se reforzó cuando conoció personalmente a Víctor Raúl Haya de la Torre en 1967, con quien tuvo múltiples oportunidades de conversar hasta la muerte de este en 1979.

El PAP era en los años sesenta la principal fuerza política popular que, tras treinta años de existencia, no había alcanzado el poder. Pese al viraje ideológico de Haya de la Torre, el PAP era visto todavía con recelo por sectores de la oligarquía peruana. Para otros, en cambio, era la única fuerza política que podía enfrentar la penetración del comunismo y el incremento de organizaciones políticas marxistas en el Perú.

86 Como buen historiador, Klaiber estableció una relación entre el tema de sus investigaciones y los problemas del presente. Su primer acercamiento a este tema se plasmó en su tesis de maestría titulada The Role of the Gonzalez Prada Popular Universities in the Development and Formation of the Peruvian Aprista Movement, presentada a la Loyola University of Chi- 
cago en $1968 .^{2}$ Tenía entonces 25 años. A diferencia de sus otras investigaciones, esta no ha sido traducida al castellano ni publicada en forma de libro. El objetivo de esta tesis era comprender al fenómeno político peruano más importante del siglo XX: el Partido Aprista Peruano, liderado por Víctor Raúl Haya de la Torre, que se perfilaba para ganar las elecciones generales de 1969.

Klaiber buscaba comprender, más allá del carisma de Haya de la Torre, en dónde residía su capacidad de movilización de las masas populares. Desde su punto de vista, esto se relacionaba con dos factores: el papel que había cumplido la educación en la difusión de las ideas del aprismo (las "Universidades Populares González Prada") y la formación de una cultura política popular aprista inspirada en el cristianismo (el "martirologio" y las "catacumbas" apristas), lo que le permitió establecer, de manera pionera, una interpretación del papel de la religión en la política y la vida peruana. Cabe destacar que esta tesis fue sustentada unos meses antes del golpe militar del 3 de octubre de 1968.

En ese sentido, el PAP era visto como la expresión de "una izquierda no comunista en América Latina”, como Klaiber la denominó en el título de su primer artículo académico publicado en 1971. En dicho artículo, llamaba la atención sobre la novedad que significaba el Partido Aprista Peruano frente a los intelectuales, partidos y movimientos antiimperialistas latinoamericanos de los últimos cincuenta años (Klaiber, 1971). Según su planteamiento, el antiimperialismo latinoamericano no solo no se había originado bajo la influencia del comunismo, sino que era anterior a él. Los mayores ejemplos eran las ideas de intelectuales como Rodó, Ugarte o Vascon-

2 Un ejemplar del mismo se encontraba en la Biblioteca de la Facultad de Ciencias Sociales de la PUCP. Obtuve una copia cuando era estudiante de historia en la década de los ochenta. Por desgracia, a esa copia le faltaba una página. 
celos, que tuvieron alcance continental e influyeron en las generaciones siguientes. Luego vendría el antiimperialismo "made in Moscow" promovido por la Internacional Comunista o Comintern. Finalmente, estaba el grupo de la "izquierda liberal" representado por el PAP.

A third group, of extreme interest but unfortunately frequently neglected by American policy makers, is the large liberal Left, which is neither pro-East nor pro-West, but which traditionally has been the standard bearer of social reform and progress in Latin America. The anti-imperialism posed by this group merits close attention because their whole approach to the question of foreign economic expansion in Latin America has been quite constructive and positive, unlike the opportunistic nationalism on the Right or the negativistic internationalism (Klaiber, 1971).

\begin{abstract}
A lo largo del artículo, Klaiber resalta, en contraste con otras corrientes, que en el caso del antiimperialismo del PAP, este está abierto a una negociación con los Estados Unidos para establecer relaciones económicas abiertas y basadas en el rechazo de los partidos de izquierda marxista.
\end{abstract}

Whatever its inadequacies, the Aprista theory of imperialistic expansion in their continent represented the first attempt to explain that phenomenon in a way which never totally endorsed uncontrolled foreign investments, as did most laissez-faire governments in Latin America in the early twenties, nor wholly rejected it as did most Marxist parties of the time. In this sense, the theory was a creative advance in both economic and political thought which profoundly influenced a whole generation of thinkers, students, politicians, and rank and file workers and peasants who make up the broad, non-communist left of Latin America (1971, p. 616).

Para sustentarlo, Klaiber hace una pormenorizada presentación de las ideas de Víctor Raúl Haya de la Torre, sobre todo en lo relacionado con el establecimiento de un Estado antiimperialista, que basado en una interpretación marxista propia de la realidad latinoamericana consideraba necesario im- 
pulsar una etapa previa de desarrollo capitalista con el apoyo del capital extranjero. Estos planteamientos correspondían a las ideas primigenias sustentadas por Haya de la Torre en los años treinta, específicamente de su libro El antiimperialismo y el Apra (1928-1936) y también en el Discurso programa de 1931 realizado en la Plaza de Acho (1963). Esto es interesante, ya que estas ideas fueron abandonadas por Haya de la Torre tras su largo asilo en la Embajada de Colombia (19481956) y recuperadas luego del golpe de Estado de las Fuerzas Armadas de 1968 como una forma de reivindicar la paternidad del programa de reformas impulsada por los militares. Inclusive, se hizo una nueva edición de El antiimperialismo y el Apra, a pesar de que este había sido oficialmente rechazado por el propio Haya de la Torre en su libro Treinta años de aprismo (1955).

Me he adelantado a hablar de ese artículo porque considero importante plantear el interés central que Klaiber tuvo en el PAP, base de sus estudios relacionados con la religión y la revolución en el Perú. Considero que, desde su llegada al Perú, Klaiber tenía la gran expectativa de que las reformas que el Perú necesitaba podrían realizarse de manera negociada entre el gobierno de los Estados Unidos y un posible (entonces) gobierno aprista encabezado por Haya de la Torre.

Esta habría sido la orientación hacia la que apuntaron sus primeros estudios sobre la historia del Perú: encontrar en la historia y en la sociedad peruana la posibilidad de una transición negociada y sin violencia, esta última presente a lo largo de la historia peruana del siglo XX.

Con la llegada de la "revolución peruana", Klaiber continuó sus investigaciones históricas sobre la estrecha relación existente entre religión y revolución en la tradición política peruana. Como dijo: "Decidí entonces dejar para un estudio especial de relación recíproca entre el liberalismo y la religión popular, no solo en el Partido Aprista, sino también en toda 
la historia moderna del Perú" (1980, p. 12). La mayor parte de sus investigaciones la realizó en Lima entre 1972 y 1975. Las fuentes fueron profusas: la Biblioteca Nacional del Perú, la colección privada de Rubén Vargas Ugarte, la biblioteca de la catedral de Lima, bibliotecas municipales y colecciones privadas de Cuzco, Puno, Arequipa, Ayacucho, Trujillo y Huaraz $(1980$, p. 12). En ese proceso, se ordenó como sacerdote en 1974, con 31 años, y bajo la tutela del obispo de Huaraz, en la sierra central del Perú, recorrió las zonas rurales del interior del país. Según su testimonio:

Desde esa perspectiva podía observar el enorme prestigio de que goza la Iglesia entre los campesinos y otros grupos de la clase popular. En distintas ocasiones he sido testigo y he participado en las grandes procesiones religiosas del Perú, tales como la del Señor de los Milagros, en Lima; Nuestra Señora de Chapi, en Arequipa; y el Señor de la Soledad, en Huaraz. Estas, y muchas otras experiencias, me han convencido de la fuerza de la religiosidad popular y de la necesidad de ver la religión y la política como realidades integrantes en la historia social y política del Perú (1980, p. 12).

A lo largo de 1975, el padre Klaiber comenzó a difundir sus investigaciones sobre el PAP en diversas revistas norteamericanas. En enero, se publicó una versión sintética de lo que sería su tesis doctoral, en la que presenta la historia del Perú de fines del siglo XIX y comienzos del XX como un largo camino hacia la consecución de la reforma en el Perú, que se comenzaría a plasmar con el surgimiento y lucha por el poder del PAP (1975a). Aunque el título del artículo (Religion

90 and Revolution in Peru: 1920-1945) hace explícita referencia a la historia del PAP entre 1920 y 1945, el arco temporal era mucho más amplio. En diciembre de 1975, publicó una versión resumida de su tesis de maestría que, en 1979, unos meses antes de la muerte de Víctor Raúl Haya de la Torre, fue traducida y publicada en el Perú (1975b).

En 1976, a los 33 años, sustentó su tesis doctoral en la Uni- 
versidad Católica de América (Washington, D. C.), titulada Religion and Reform in Peru, 1824-1945, la cual estuvo dedicada a su director de tesis Antonine Tibesar, OFM, reconocido peruanista norteamericano de la orden de los franciscanos, sin cuyos conocimientos y contactos la tesis no habría llegado a buen puerto (1980, p. 13). Terminado su periodo de formación, el padre Klaiber se estableció definitivamente en el Perú. Comenzó entonces a enseñar en la Pontificia Universidad Católica del Perú, donde continuó trabajando hasta su muerte. Allí ejerció diversos cargos, entre ellos el de jefe del Departamento de Humanidades.

$\mathrm{Al}$ año siguiente, se publicó su tesis doctoral como libro con el título modificado de Religion and Revolution in Peru, 18241976 (Notre Dame, Indiana: University of Notre Dame Press, 1977). Llama la atención el cambio en el título del libro del término "reforma" por "revolución". Como veremos más adelante, el uso del concepto de "reforma" en el título del libro se relacionaba a su interés por estudiar a la "élite reformista” peruana en la historia contemporánea del Perú en cuanto a su incapacidad para identificarse con los sectores populares y promover los cambios que el país necesitaba. En ese sentido, el Perú, pese a su larga historia de protesta social y rebeldía, no se había caracterizado por la revolución. como sí había ocurrido en otros países de América Latina como México, Cuba y Bolivia. El Perú parecía así atrapado en una especie de "limbo" histórico. ¿Por qué cambiar el título, entonces?

Establecido en el Perú, en 1978, publicó un breve artículo referido a la historia del PAP entre los años 1923 y 1945, que en su tesis doctoral correspondía a los capítulos 6 y 7 . Años después, el libro tuvo dos ediciones en castellano: la primera en 1980 basada en el libro en inglés, y la segunda en 1988, actualizada con un nuevo prefacio y un nuevo capítulo; ambas publicadas por la Universidad del Pacífico, que también contaba con la presencia de la Compañía de Jesús. Cabe agre- 
gar que en la carátula de las ediciones en castellano la palabra "revolución” resaltaba en color rojo. Nuevamente, ¿por qué? No lo sabemos.

En la introducción del libro, Klaiber parte de una premisa muy clara: el Perú era una nación, pero aún estaba en la búsqueda de una identidad que integrara a la "multitud de diferentes culturas, mezclas raciales y clases sociales, las cuales tan sólo en el siglo XX han comenzado a forjar una identidad y un destino comunes" (1988b, p. 15). Eso no había sido posible anteriormente porque la élite reformista criolla que gobernaba el país, imbuida de las ideas de la ilustración, el positivismo y el racionalismo, no había podido establecer lazos con las clases populares, "a las cuales pretendían integrar dentro de la nueva cultura nacional” (p. 16). Para Klaiber, solo "existía una herencia común que todos los peruanos compartían, y esta fue la religión católica que los misioneros del siglo XVI habían predicado e implantado con bastante éxito en las regiones más remotas del país" (p. 16). Sin embargo, las prácticas religiosas de los sectores populares, especialmente de los indígenas, eran muy diferentes a la religiosidad oficial practicada por la élite reformista criolla. "Esta subcultura religiosa, que sigue floreciendo por toda América Latina en el siglo XX, ha sido llamada 'religiosidad popular' o 'catolicismo popular"' (p. 17).

Sobre la base de esta premisa, Klaiber se propuso como objetivo "examinar la relación mutua entre el mundo religioso de la élite reformista y las clases populares” entre 1824 y 1976. $\mathrm{Su}$ conclusión principal fue que solo tres élites reformistas criollas del siglo XX llegaron a identificarse con los intereses de las clases populares: el Partido Aprista Peruano, las Fuerzas Armadas que tomaron el poder en 1968 y la Iglesia católica (pp. 20-21). Desde su punto de vista, el de mayor éxito y persistencia fue, sin duda, el PAP. El reformismo militar terminó muy pronto, justo al momento de publicarse la primera edición de su libro; mientras que la Iglesia católica es 
una fuerza política, pero no un partido político. Ese decantamiento lógico del padre Klaiber por el PAP se mantendría aparentemente incólume hasta el final de sus días, como se verá más adelante.

Pero, ¿cuál había sido el recorrido histórico en el Perú entre religión y política? Klaiber lo remite a los orígenes de nuestra República, cuando la élite reformista representada por los liberales decimonónicos no fue capaz de lograr el apoyo popular. $\mathrm{Al}$ respecto, afirma:

En comparación con otros países latinoamericanos, el anticlericalismo liberal en el Perú fue relativamente suave, pero nunca una causa popular. Esto se debe, en parte, a la fuerza de la cultura y la tradición hispánica entre la clase alta y, en parte, a la fuerza del catolicismo entre los mestizos e indios de clase baja (p. 24).

Aunque los liberales consiguieron algunas victorias a favor de su causa desde la independencia, no lograron cambiar las actitudes populares en lo inmediato, pero sus ideas se convirtieron en los dogmas de movimientos reformistas posteriores (pp. 24-25). Esto lo demuestran los casos de Manuel Lorenzo de Vidaurre, Francisco de Paula González Vigil y Francisco Javier Mariátegui. En conclusión, dice Klaiber, "ni Vidaurre, Vigil, Mariátegui, ni los demás liberales, podían imaginar un día en que el cristianismo católico, en los términos de Manheim, dejara de ser una ideología legitimando el orden establecido, y se convirtiera en una utopía, anunciando un nuevo orden social mientras que el antiguo orden todavía domina” (p. 41).

El caso de Manuel González Prada no fue muy distinto. "Ya sea porque fuera un individualista algo solitario o porque las condiciones sociales del país todavía no eran propicias, González Prada no creó un movimiento propio, ni dejó en herencia ningún programa concreto para futuros reformadores" ( $\mathrm{p}$. 43). Sin embargo, fue el eslabón principal entre los reforma- 
dores liberales del siglo XIX y los movimientos sociales del siglo XX (p. 44). Inició su actividad política pública después de la guerra del Pacífico, fue fundador del Circulo Literario y del partido Unión Nacional, pero estos no lograron muchos adeptos. Si bien la falta de adhesión popular la atribuían a "la ignorancia de las masas populares", lo cierto es que "no obstante el hincapié que hicieron en las metas sociales, los reformadores nunca realizaron un esfuerzo serio para atraer al partido a los obreros u otros grupos de las clases populares" (p. 49). Lo cierto es que, en términos de discurso, González Prada expresaba los principios de un anticlericalismo radical, profundamente ateo y positivista, que derivó en el anarquismo de su madurez. Aunque se convirtió en una voz solitaria, era "el portavoz de la reforma", según Klaiber, pese a que se mantuvo muy distante de los sectores populares, sobre todo de la mayoría indígena. "Las ideas de González Prada acerca de la religión y la reforma ciertamente tuvieron considerable influencia en la élite reformista; pero no reflejaron necesariamente las actitudes de las clases populares del Perú, sobre todo de los indios" (p. 66).

Lejos de una visión paternalista o una historia desde arriba, Klaiber también estudió el punto de vista de las clases populares, sobre todo de los indios, respecto de la religión. A falta de fuentes escritas directas, estudió las principales protestas populares indígenas de fines del siglo XIX y principios del XX. "Aunque hay poca documentación sobre estos movimientos, lo que existe es suficiente para echar una luz 94 sobre las actitudes de los indios hacia la Iglesia y la religión" (p. 72). Esto era de suma importancia para el objetivo de su investigación, porque se trababa de demostrar que la religión era el único puente que podía unir como nación a las élites reformistas y las clases populares. En esta dirección, estudió principalmente las rebeliones de Huancané (1866-1868), Huánuco (1895), Huanta (1896), Puno (1895-1897) y especialmente el levantamiento de Huaraz (1885), encabezado por el amauta Atusparia y Uchu Pedro. En todas ellas, el 
padre Klaiber encuentra la adhesión de mestizos e indios a la Iglesia y a la religión, por lo que concluye que estos "habían llegado a experimentar y a aceptar como normal una compatibilidad entre el catolicismo popular y su lucha por la justicia social" (p. 94). El impacto de estas provocó en la élite reformista liberal una nueva cruzada en defensa del indio que se expresó en el movimiento indigenista de fines del siglo XIX y principios del XX.

Al igual que la prédica de González Prada, Klaiber consideraba al movimiento indigenista no solo como un "momento de redescubrimiento del indio", sino también como un "eslabón entre los liberales del siglo XIX y los reformadores sociales del siglo XX" (p. 96). A diferencia de otros momentos similares, la prédica del radicalismo político unió a Lima con las provincias. Se trató también de un movimiento de expresión de la clase media provincial, escribieran desde las provincias o desde Lima (p. 97), y que se manifestó de diferentes formas.

En primer lugar, se manifestó a través del romanticismo literario, como son los casos de Narciso Aréstegui, Clorinda Matto de Turner y José Itolarrares. En segundo lugar, a través de estudios científicos, ensayos y artículos "en torno a distintos aspectos del imperio incaico o a la situación actual de los indios, con el objeto de proponer reformas y mecanismos para ponerlos en práctica" (p. 104); entre estos se encuentran Mercedes Cabello de Carbonera, Alejandro Maguiña, Pedro Yrigoyen, Dora Mayer, Hildebrando Castro Pozo. En tercer lugar, los representantes del "indigenismo político" que, "sobre todo, miraban hacia los Andes como la fuente de una revolución venidera que sacudiría las tradiciones y que haría revitalizar al país con la energía juvenil de la raza indígena" (p. 108), expresados en el Grupo Resurgimiento (Cuzco) y el Grupo Amauta (Lima). Finalmente, están aquellos que tuvieron un particular interés en estudiar la relación entre la "liturgía católica y el culto incaico", que corresponden a los 
casos de Emilio Romero, José Uriel García, César Falcón y Ernesto Reyna, entre otros.

¿Cuáles fueron las consecuencias de esta toma de conciencia? Klaiber plantea fundamentalmente dos. En primer lugar, "los indigenistas se dieron cuenta de la necesidad de cuestionar sus propios conceptos apriorísticos acerca de los valores, las creencias y las capacidades de las clases populares del Perú" (p. 118). En segundo lugar, "La contribución principal de los indigenistas al pensamiento social fue la de dar forma y substancia a la imagen de los indios y mestizos de la clase popular del Perú. Armados con este conocimiento de su propio pueblo, los revolucionarios sociales de las siguientes décadas estaban mejor capacitados para elaborar sus planes y llamar al pueblo a sublevarse" (p. 119).

Esta tarea se la planteó, por primera vez, según Klaiber, José Carlos Mariátegui La Chira, a quien señala como representante de un "marxismo espiritual", que se expresaba en "La fusión ecléctica de elementos espirituales y marxistas en los ensayos y artículos (...) sobre la religión, el arte y la política (...)” (p. 120). Para defender esta tesis, Klaiber resalta los aspectos biográficos, sobre todo juveniles, en los cuales Mariátegui expresó su preocupación religiosa. De particular importancia es su experiencia mística en el retiro que realizó en el Convento de los Descalzos y sus escritos sobre la religiosidad popular en Lima, en particular, su artículo sobre la procesión del Señor de los Milagros (pp. 125-126). Ya en

96 su etapa europea, Klaiber resalta a aquellos autores europeos que influyeron en su obra y que considera "profetas":

Hay dos denominadores comunes fundamentales entre los autores que Mariátegui estudió en Europa y, más tarde, en el Perú. Todos eran profetas que pregonaron la declinación y la caída del capitalismo occidental y la emergencia de un nuevo orden social, y se rebelaron contra los sistemas filosóficos del determinismo y racionalismo, que reinaron en el siglo XX. El voluntarismo pagano de 
Nietzche, el élan vital de Henri Bergson y el mito de la huelga general de Georges Sorel, reflejaron la aparición de un concepto nuevo y dinámico del hombre, la cultura y la historia (p. 129).

Además de analizar la influencia de estos dos últimos autores (Bergson y Sorel), Klaiber realizó un análisis pormenorizado del ensayo "El factor religioso" publicado en su célebre libro, 7 ensayos de interpretación de la realidad peruana (1928), en el que "Mariátegui estudió, formalmente, el papel de la religión en la historia peruana" y "se aprecia mejor después de analizar su concepto de 'religión', el cual emerge a partir del concepto soreliano de 'mito' en la mayoría de sus otros artículos y ensayos” (p. 130). Como conclusión de este análisis, Klaiber sostiene que:

Una de las principales contribuciones a la historia de las ideas en el Perú fue la de dar un sentido más amplio y enjundioso a las palabras 'religión' y 'política'. Al hacerlo, echó una luz positiva sobre la religiosidad andina y el catolicismo popular costeño, los cuales han sido considerados como obstáculos a la reforma radical por muchos de sus promotores de esta cultura (p. 130).

En ese sentido, "La visión de Mariátegui acerca de la unidad entre la política y la religión (...) nació en la agonía y la soledad de una celda ascética y en el apretar de una muchedumbre en una procesión religiosa en algún momento de su pasado, que parece que nunca había dejado atrás" (p. 147).

Los dos capítulos dedicados a Víctor Raúl Haya de la Torre y al Partido Aprista Peruano corresponden al punto nodal del libro, ya que Klaiber consideraba que estos habían logrado la adhesión de los sectores populares al lograr unir religión y política. Al margen de las opiniones tan diversas sobre el PAP, Klaiber sostenía dos certezas: "que el Partido Aprista fue, sin duda, el primer verdadero partido político popular en la historia del país" y que "aún dada su alta concentración regional entre los braceros de las haciendas azucareras en la costa norte, el APRA llegó a ser, más que cualquier otro mo- 
vimiento, hasta los años cincuenta, el único verdadero partido nacional del Perú" (p. 150). La explicación central de esto, para Klaiber, era el carácter populista del partido, que había hecho posible abrir "sus brazos para recibir a todas las clases explotadas, tanto las medias como las populares" ( $\mathrm{p}$. 151). Eso no significó la inexistencia de tensiones entre los intelectuales que dirigían el partido y los sectores populares o entre estos en el interior del partido, lo que explicaría los constantes virajes políticos e ideológicos del aprismo.

En ese sentido, Klaiber divide la historia del PAP en dos momentos. En el primero, entre 1919 y 1931, el naciente aprismo mostró "algunas tendencias anticlericales"; y en el segundo, entre 1931 y 1945, "descartaron casi por completo el anticlericalismo de su juventud y abiertamente se dirigieron a los sentimientos religiosos de sus partidarios" (p. 156). "Fue sobre todo durante esta segunda etapa cuando los dirigentes apristas se percataron de que el catolicismo popular, lejos de ser un obstáculo para la reforma, (...) podría, en realidad, ser un resorte clave para galvanizar al pueblo hacia la lucha y la resistencia contra los regímenes dictatoriales de Sánchez Cerro y sus sucesores (p. 156).

Para entender estas dos etapas, Klaiber analiza la relación entre el naciente aprismo y el movimiento obrero anarco sindicalista, claramente anticlerical, a través de la experiencia de las Universidades Populares González Prada y la protesta contra la consagración del Perú al Corazón de Jesús, el 23 de mayo de 1923. Respecto al primero, Klaiber sostuvo: "Esta diversidad tan amplia de composición social, cultural y de grado de concientización política dio origen a una mezcla curiosa del radicalismo 'González Pradista' con un cristianismo bíblico y sencillo dentro de la Universidad Popular, anticipando un fenómeno semejante en el Partido Aprista unos años después" (p. 161). Respecto al segundo, la protesta del 23 de mayo, claramente anticlerical pese a que Haya de la Torre utilizó recursos del catolicismo popular en los discursos 
de ese día, impulsaría una severa y dura campaña del gobierno y la Iglesia contra el líder estudiantil que se extendió hasta su campaña electoral a la presidencia en 1931. No fue en este momento, sino en el siguiente que Haya de la Torre y el aprismo lograron conectar con la religiosidad popular.

El sector más agresivo contra la candidatura de Haya de la Torre en las elecciones de 1931 era el clero, que se alimentaba de las ambigüedades del PAP frente al tema religioso y del creciente apoyo que católicos, sobre todo de los sectores populares, le daban al candidato aprista. Esto generó un amplio debate a través de la prensa, los folletos y los discursos públicos. Tras su derrota electoral, Haya de la Torre fomentó lo que Klaiber define como el "culto al martirio" (p. 185), en un gesto retórico en el cual usando referencias bíblicas y comparandose con el martirio de Jesús, atraería cada vez más apoyo popular. Esta situación se agudizó tras las insurrecciones apristas de Trujillo y Huaraz en julio de 1932, como consecuencia de la brutal represión contra el aprismo que se extendió a los siguientes gobiernos. "El acontecimiento más importante que transformó la lealtad secular en una lealtad casi religiosa dentro del Partido Aprista fue la revolución y la subsecuente masacre de Trujillo" (p. 186) y "Si la tragedia de Trujillo dio origen al culto del martirio aprista, fue la insurrección de Huaraz la que le proporcionó al movimiento su lema cúltico" (p. 190). Ambas experiencias, "dieron origen a numerosos cantos, lemas y leyendas que formaron parte del folklore aprista. Esta literatura cumplía en gran parte la misma función apocalíptica para los primeros cristianos: la de animar a los fieles a seguir siendo firmes en la lucha" (p. 191). Otro campo en el que se fomentó este "culto al martirio" fue la literatura. "Durante los años treinta, escritores y poetas apristas formaron su propio grupo dentro del partido, 'La Liga de Escritores Revolucionarios del Perú, que incluía muchos autores destacados, tales como Alberto Hidalgo, Magda Portal, Serafín del Mar, Ciro Alegría y Esteban Pavletich" (p.193). 
Sin embargo, la experiencia de salir de las "catacumbas apristas" en 1945 marcó un periodo de transición en el PAP, que se expresó inicialmente en los acuerdos tomados en la Convención Nacional Aprista de 1942, donde se abandonaron puntos importantes del programa aprista, entre ellos, la separación entre Iglesia y Estado (pp. 199-200). Este giro no será menor:

Si el APRA cambió o no en su nueva política de buscar una reconciliación en los grupos de clase media y alta, es el tema de un debate continuo. Mas cierto es que, con la aparición del cristianismo social en el Perú en los años de posguerra, con el aumento de la secularización entre los católicos de clase media, en general, y con la fuerte posición anti-comunista del APRA, el pertenecer al Partido Aprista ya no representaba el audaz acto casi religioso que significaba en los años treinta. (...) el APRA comenzó a parecer más un partido católico tradicional que un movimiento que se inició en un acto público de desafío contra el Arzobispo de Lima (pp. 200-201).

Esto fue sancionado en el discurso de Haya de la Torre en el famoso mitin de la Plaza San Martín, el 20 de mayo de 1945, donde "Haya ofreció una reconciliación con los enemigos del APRA" (p. 202). Como señala Klaiber, "El 'Calvario Aprista' había terminado y, con él, la primera etapa del gran experimento del populismo" (p. 202). Nuevas fuerzas surgieron en las décadas siguientes "para desafíar el dominio casi total del APRA sobre las clases populares costeñas y para ampliar el proceso de integración nacional", estas fueron las Fuerzas Armadas y la Iglesia católica (p. 202).

Como se ha señalado, Klaiber consideraba que, además del PAP, las Fuerzas Armadas y la Iglesia católica eran quienes mejor habían comprendido la relación entre religión y revolución en el Perú, lo que impulsó momentos de acercamiento de estos con los sectores populares urbanos y rurales. Un momento clave de disputa entre estas "tres fuerzas institucionales" por obtener el fervor y el apoyo de las clases populares fueron los años del gobierno militar que se inició en 1968. 
De las tres, la Iglesia católica tuvo las mejores perspectivas: "Aunque el régimen militar que tomó el poder en 1968 ha efectuado profundas y en muchos casos irreversibles reformas, ha fracasado notablemente en el intento de crear una ancha base de apoyo popular en su favor" (p. 204). Mientras que "tan solo la Iglesia ha podido penetrar con éxito en las reservas de las clases populares actualmente politizadas. Sobre todo en los pueblos jóvenes (...) que rodean las ciudades costeras, y en la sierra, la nueva Iglesia ha logrado identificarse con las aspiraciones de las clases populares (...)” (p. 205). Klaiber define a los militares del 68 de la siguiente manera:

Aunque representaron distintos tipos de personalidad y de orientaciones ideológicas, estos hombres tipificaron a la nueva élite militar en el Perú: bien preparados, pragmáticos, nacionalistas, anti-comunistas, pero profundamente preocupados por la justicia social y orientados hacia el trabajo en equipo en su manera de gobernar y llevar a cabo sus reformas (pp. 213-214).

Además, estos líderes de la "revolución peruana” podían ser divididos en dos grupos en términos religiosos: católicos culturales y cristianos comprometidos. Los primeros, representados por el propio general Juan Velasco Alvarado, pueden ser definidos como expresión de "la recepción de ciertos sacramentos de la Iglesia, o la observancia de ciertos ritos de la religiosidad popular, más porque son tradiciones familiares o sociales que por las verdades religiosas que encierran" (p. 214). Los segundos, estaban representados por los oficiales, como los generales Leonidas Rodríguez Figueroa o Jorge Fernández Maldonado, que se formaron en diversas instituciones religiosas como los cursillos de cristiandad o habían estudiado en colegios privados dirigidos por órdenes religiosas, profundamente marcados por el idealismo cristiano (pp. 216-217). Este último grupo tuvo amplia influencia en documentos claves de la revolución castrense, como La ley general de educación, Las bases ideológicas de la revolución peruana y Lineamientos de politica de población del Perú. La idea cen- 
tral que estaba detrás de estos documentos era la creación de una "democracia social de participación plena", que, como hemos visto, fracasó.

En cambio, la Nueva Iglesia tuvo mayor éxito que los militares "al proyectar una imagen positiva de sí misma y al asumir un papel directivo entre las clases populares en la lucha por conseguir una mayor participación económica y política” (p. 221). Esto fue posible porque la Iglesia buscó influenciar en la orientación de las reformas e identificarse con los sectores populares. Esto último se promovió a través de diversas organizaciones religiosas, la publicación de documentos que impulsaban el humanismo cristiano y la acción pastoral, sobre todo en la región sur andina, que Klaiber analiza someramente. Esto motivó una disputa entre el gobierno militar y la Iglesia por lograr mayor influencia en las zonas urbanas marginales de Lima, que tendría su momento más álgido con el caso Bambarén-Artola en la zona conocida como Pamplona, en el actual distrito de San Juan de Miraflores. Este caso, aunque terminó en buenos términos, distanció a la Iglesia y a los sectores populares del gobierno militar. Un corolario de todo esto es que los sectores de la Iglesia que estaban a favor de "la necesidad de evangelizar usando las formas de la religiosidad popular" y de que "la Iglesia tiene que predicar su mensaje de justicia social dentro del contexto de las prácticas tradicionales del pueblo", lograron una mayor inserción en los sectores populares (pp. 235-236).

\section{Una nueva edición de Religión y revolución en el Perú}

En el prefacio de la segunda edición de Religión y revolución en el Perú, aparecida en 1988, Klaiber manifestaba que, a pesar del tiempo trascurrido, los hechos habían demostrado la principal tesis del libro:

Ciertos acontecimientos ocurridos después de la primera edición en inglés de esta obra (1977), y de su primera edición castellana 
(1980), tales como la presencia militante de los cristianos en la revolución sandinista, la aparición de una "izquierda cristiana" en América Latina y particularmente en el Perú, el debate en torno a la teología de la liberación, la visita al Perú en 1985, parecen confirmar la tesis fundamental de la obra: que en América Latina religión y política se influyen mutuamente y no se puede comprender la política sin tomar en cuenta el factor religioso (1988b, p. 11).

En esta dirección el padre Klaiber incluyó un nuevo capítulo titulado "Profetas y populistas: Alan García, la Izquierda Católica y la teología de la liberación”; con nuevas fuentes, como entrevistas a dirigentes del PAP (Nicanor Mujica Álvarez Calderón, Carlos Roca Cáceres y otros) y de Izquierda Unida (Henry Pease y Marcial Rubio). Además, actualizó la bibliografía: "También ha sido enriquecida la bibliografía con la inclusión de títulos de artículos y libros de mayor relevancia que han ido apareciendo desde la primera edición" (p. 11). Podemos suponer que, con el tiempo transcurrido, el PAP y la Iglesia Católica continuaban expresando o buscando representar a las clases populares, mientras que las Fuerzas Armadas que gobernaron el país entre 1968 y 1980 habían desaparecido del escenario. Más bien, como veremos, hizo su aparición un nuevo actor: la "Izquierda Católica", para disputar, sobre todo al PAP dicha representación popular.

Como señala el título, el capítulo está dividido en tres partes. El primero está dedicado al entonces joven presidente de la República, Alan García Pérez, de quien dice: "En muchos sentidos Alan García es el heredero de un estilo político ya ensayado mucho tiempo antes por su mentor y maestro, Haya de la Torre" (p. 219). Hace un recorrido por su trayectoria política desde su adolescencia cuando fue incorporado al círculo íntimo de Haya de la Torre, quién ya estaba formando la dirigencia que lo sucedería en la dirección del PAP. "Fue en este círculo privilegiado donde Alan conoció de cerca la mente y el estilo del hombre que los apristas con- 
sideraban como un hermano mayor y un padre de familia" (p. 219). Allí también desarrolló las habilidades políticas e intelectuales que lo llevarían a la presidencia de la República: "Sobre todo, Alan García posee un instinto agudo para sondear el 'clima' político y para sentir cuál es el pulso popular de un momento a otro" (p. 221). Como parte de esta estrategia, Alan García realizó múltiples comentarios políticos con referencias religiosas, sobre todo en el contexto de la visita del papa Juan Pablo II en 1985, que continuaron durante el gobierno aprista.

Cabe resaltar que el periodo que comenta el padre Klaiber abarca hasta fines de 1987, ya en pleno gobierno aprista. Si bien es entendible que su intención era centrarse en el tema principal del libro, sorprende que no haya hecho, como en capítulos anteriores, una revisión de las principales críticas al aprismo ni referencia alguna a hechos controversiales que ponían en duda el discurso político-religioso del joven presidente, como la masacre de los penales de junio de 1986. Este es, quizás, un rasgo destacable de su obra sobre la historia contemporánea del Perú: su distanciamiento de los hechos políticos todavía vigentes en la coyuntura. Un rasgo propio de una concepción tradicional de la historia que la entiende como cientifica, racional y objetiva que, justamente, en esos ańos estaba siendo severamente cuestionada por una interpretación de la historia más militante y comprometida con los sectores populares. Sobre este punto volveré al final del artículo.

Respecto a la denominada Izquierda Católica, la caracteriza como "formada en el seno de los partidos de izquierda y del movimiento popular y sindical a nivel nacional" y que "se inspira directamente de las enseñanzas sociales de la Iglesia y porque casi todas sus figuras principales están vinculadas íntimamente con organismos y movimientos de la Iglesia". Además, "un núcleo importante de sus portavoces se ha formado y ejerce la docencia en la Universidad Católica del 
Perú". Asimismo, "Casi todos comparten ciertos rasgos comunes: provienen de familias católicas y de colegios religiosos y han participado en los mismos movimientos eclesiales o en algún momento en la Democracia Cristiana" (pp. 223224). Según Klaiber, el fenómeno político obedecía a dos factores: "primero, los cambios ocurridos en la Iglesia que, a partir de los ańos 60 , exhortó a los católicos para que tomaran un rol protagónico en la construcción de un mundo más justo, pero favoreciendo sobre todo a los más pobres y débiles; y segundo, los cambios producidos en la misma izquierda política, que tras sus propias crisis internas, se hacía cada vez más pluralista y nacionalista, menos sectaria y dogmática" (p. 225). Entre los representantes de esta izquierda católica destacaba el abogado Alfonso Barrantes Lingán, de quien hace una elogiosa reseña.

La opción del padre Klaiber por decantarse por este sector de la izquierda de los años ochenta es clara porque, como se dijo antes, era expresión de una izquierda "menos sectaria y dogmática" frente a la denominada "Izquierda Radical" encabezada por el principal dirigente del Partido Unificado Mariateguista, el recordado Javier Diez Canseco. También porque

(...) ellos desempeñan un rol protagónico en favor de la unificación de la misma izquierda. Su propia formación humanística y cristiana los preparó para que fueran agentes de la conciliación, intelectualmente y en el plano de las relaciones humanas. Son beneficiarios de una larga y rica tradición católica que se ha caracterizado por su inquietud de buscar la integración armoniosa entre la fe y el mundo (p. 230).

La tercera parte está dedicada a la teología de la liberación, uno de los temas más relevantes de su obra posterior dedicada al estudio de la Iglesia en el Perú y América Latina. En este caso, se centra en el debate abierto en el contexto de la visita papal sobre el significado de la teología de la liberación, tan identificada con el padre Gustavo Gutiérrez. 
Los puntos más controvertidos de la teología de la liberación son el uso de ciertas categorías marxistas, tales como la lucha de clases; el reduccionismo de ciertos temas bíblicos a un plano puramente social y político; y la aceptación del uso, si bien no de la violencia, al menos de algún tipo de presión o de fuerza para defender o conseguir los derechos de los pobres (p. 231).

Lo que más preocupaba a los sectores conservadores era que la teología de la liberación había "traspasado los claustros y los seminarios y las universidades y se había convertido en la bandera de todo un movimiento eclesial" en América Latina y en muchos lugares del tercer mundo. Klaiber, sostiene que el Vaticano, bajo la influencia del entonces cardenal Ratzinger, responsable de la Sagrada Congregación para la Doctrina de la Fe, no tuvo una actitud ni de condena oficial ni de aprobación condicionada. Y esto respondió a tres razones: la primera, a la existencia de distintas teologías de la liberación; la segunda, la teología de la liberación impulsada por el padre Gustavo Gutiérrez siempre "ha favorecido el mantener los lazos de la unión entre los fieles y la jerarquía”; la tercera, que más que una teología politica, se trata de una teología pastoral que "se propone orientar y consolar a un pueblo marginado que busca soluciones a las crisis diarias que surgen en medio de la lucha por la existencia”; y el cuarto, quizás el más importante de todos, "en vez de favorecer la conversión de las personas al marxismo, más bien se ha convertido en una alternativa para el cristiano frente al marxismo" (p. 233).

Esta actitud del Vaticano, que podríamos llamar condescendiente, respondía, según Klaiber, a que en el Perú no había el ambiente "de rebeldía o frialdad que había experimentado en Nicaragua y en Holanda”. Nosotros podríamos agregar que, en el Perú de entonces, no estábamos al borde o en plena efervescencia revolucionaria. La relación entre revolución y religión era clara en esos momentos en Centroamérica, donde las experiencias revolucionarias de Nicaragua, El Salvador o Guatemala no solo habían movilizado a los fieles cristianos 
a luchar contra dictaduras brutales o la intervención norteamericana, sino también a la jerarquía de la Iglesia en defensa de los derechos humanos y contra la injusticia social. En ese sentido, Klaiber consideraba que el caso peruano se movía dentro de la posibilidad de reformar el país a través de la relación entre la religión y la política, más no de la revolución, como en otros casos de América Latina.

Pese a este nuevo capítulo, Klaiber no hizo modificaciones ni agregados a sus conclusiones. Como hemos podido ver, este último capítulo mantenía las expectativas establecidas en la primera edición del libro. ¿Cuál fue la importancia y el impacto que tuvo? Por ahora, haré una primera aproximación. ${ }^{3}$

Este es un libro de gran importancia para la historia política e intelectual peruana, aunque tuvo poco impacto en su momento y pasó casi desapercibido en el Perú. La edición en inglés solo tuvo una reseña en español, discrepante pero elogiosa, escrita por el historiador norteamericano, Peter Klarén (1978), especialista en la historia del PAP, un año después de su publicación, en la revista Histórica, de la PUCP.

Además de la reseña de Klarén a la edición en inglés, el libro tuvo tres reseñas más. La primera, del padre Armando Nieto S. J. (1980) a la primera edición peruana en la revista Histórica de la PUCP. La segunda, de la socióloga Imelda Vega Centeno (1980) en la revista Socialismo y Participación, del Centro de Estudios para el Desarrollo y la Participación (CEDEP), ambos dirigidos por Carlos Franco. Y la tercera, escrita por el historiador norteamericano David Parker (1987), esta vez a la segunda edición peruana, en la revista Apuntes de la Universidad del Pacífico. Esta última es la más extensa y la más crítica. Cabe resaltar que la PUCP y la UP están estrechamente vinculadas a la Compañía de Jesús y que

3 Queda pendiente la tarea de terminar de revisar y comentar las reseñas publicadas en el Perú y los Estados Unidos. 
el padre Klaiber fue miembro de ambas; mientras que el CEDEP era una organización no gubernamental para el desarrollo impulsada por intelectuales que habían colaborado en la formulación e implementación del programa de reformas del gobierno militar.

¿Por qué tuvo tan pocos comentarios en el Perú? Quizás, en el caso de la edición de 1980, influyó el contexto político del país. Ese año no solo se realizaron elecciones democráticas después de doce años de dictadura, sino que la crisis económica del país se agudizó y se inició el conflicto armado interno que desangró al país por casi veinte años. El debate político e ideológico se imponía con mayor fuerza que el académico y el público. En el caso de la segunda edición de 1988, considero que responde a la gran expectativa que tuvo la publicación, ese mismo año, de su primer libro dedicado al estudio de La Iglesia en el Perú. Su historia social desde la independencia (1988a). De esta manera, el padre Klaiber continuaba la tradición historiográfica iniciada por otro sacerdote jesuita, Rubén Vargas Ugarte S. J. Este libro tuvo mayor impacto y repercusión, incluida una edición en inglés (1992) y una nueva edición ampliada en castellano (1996) publicada por el Fondo Editorial de la PUCP.

\section{Colofón}

El padre Klaiber partió el 4 de marzo de 2014. Hasta su último día no dejó de pensar en la realidad de nuestro país. Aunque había dejado de escribir sobre la política de nuestra historia reciente, volvió a tocar este tema tangencialmente en los años que siguieron. Con el comienzo del siglo XXI, mantuvo su fe en que el aprismo, el partido que mejor había expresado como parte de la élite reformista peruana la unidad entre política y religión, haría posible la tan ansiada unidad nacional que enrumbara al Perú hacia el futuro. Por ello, no quisiera terminar sin analizar un último y particular comentario del padre Klaiber sobre el PAP en tanto expresión preclara de la relación entre religión y política en el Perú. 
En noviembre de 2001, se llevaron a cabo cuatro jornadas académicas organizadas por el Seminario Interdisciplinario de Estudios Andinos (SIDEA), con el título El miedo en la historia del Perú, en las que participó el padre Klaiber con el tema del miedo al APRA. En el 2005, Claudia Rosas Lauro, organizadora del evento y editora del libro que recoge las ponencias, reseñó así el artículo del padre Klaiber:

Klaiber nos entrega una sucinta historia del aprismo, la naturaleza de su doctrina y su cimbreante trayectoria durante los primeros cincuenta años de su existencia. Con esta base propone las razones del antiaprismo, que en varias oportunidades ha generado un masivo voto negativo para el partido en cuestión. Sobresalen en este análisis sus relaciones con la izquierda peruana y los partidos de derecha, y la ambivalencia de sus posiciones, en las que el autor encuentra las razones de su rechazo, especialmente si se le suma "una mezcla de religión y política" que parece caracterizar al APRA (Rosas, 2005, p. 12).

Como puede verse en esta certera reseńa, Klaiber no había cambiado su visión del PAP más de 15 años después de publicada la segunda edición de Religión y revolución en el Perú. En su breve texto, Klaiber reitera la idea de que lo que distingue al PAP de otros partidos, sobre todo de la izquierda, era su exitosa combinación de religión y política, aunque la revolución había sido ya olvidada hace mucho tiempo atrás, cuando llegó al poder por primera vez encabezado por Alan García Pérez.

En fin, el APRA se había convertido en un movimiento cuasimesiánico, con sus símbolos y lemas inspirados en el catolicismo popular de los mismos apristas. Este fenómeno fue peculiar para un partido considerado de izquierda. (...) Así, el APRA se fortaleció con un elemento que no era originalmente parte de su "mística". Entre los no apristas, esa mezcla de religión y política fue otro motivo para sentir miedo. Si el APRA fuera solo un movimiento comunista o fascista, uno podría comprenderlo y enfrentarlo. Pero, ¿qué hacer frente a un movimiento que había absorbido 
elementos del cristianismo, no tanto por sus programas políticos, pero sí en la práctica y la conducta de los apristas? (Klaiber, 2005, p. 263).

Esta relación seguía siendo la base que explicaba la persistencia del PAP que, desde la perspectiva de Klaiber, haría que el PAP perdurara por mucho tiempo más. Los viejos partidos de la democracia liberal de los años ochenta habían desaparecido y los nuevos "partidos" no llegaban a convencer. Solo el PAP parecía perdurar a lo largo del tiempo como el joven Dorian Gray, salvándose de la extinción.

Uno no hace esta pregunta acerca de otras agrupaciones políticas con la misma preocupación o grado de ansiedad. Desde luego, la izquierda, al menos en la forma en que se presentó en la década de 1970 hasta la de 1990, ya no existe. Muchos otros partidos han desaparecido. Han surgido nuevos partidos, pero justamente por ser nuevos, no inspiran confianza acerca de su estabilidad y capacidad de durar mucho tiempo. Finalmente, en medio de todo queda el APRA, cuya extinción ha sido anunciada muchas veces. Curiosamente, setenta y un años después de su fundación, la pregunta que más preocupó a los peruanos en el año 1931 sigue siendo lo que más preocupa a los peruanos del siglo XXI: "¿Qué es el APRA?"; o bien: "si el APRA llega al poder, ¿qué va a hacer?" (2005, p. 264).

Esto fue escrito mucho antes del segundo gobierno de Alan García Pérez, 2006-2011. Pero es claro que sus previsiones no fueron correctas: el PAP, como los otros partidos de las

110 décadas de los sesenta a los ochenta, ya no existe hace mucho tiempo. Dividido en fracciones, dirigido por una minoría leal al presidente del partido, reducida su histórica célula parlamentaria a una minoría mediocre, aliada al fujimorismo sin la cual su peso político sería nulo, y con su principal líder muerto, se puede decir que el PAP en el cual Klaiber apostaba, ha muerto. ¿Renacerá de sus cenizas como el ave fénix? Es posible, pero el PAP ya no será el mismo. 
Hoy en día, podemos encontrar severas discrepancias no solo con respecto a los ańos y personajes tratados en los últimos capítulos de este libro, con su interpretación de la situación política y social de los ańos correspondientes a sus últimos años de vida y, sobre todo, sus previsiones de futuro. Pero de lo que no se puede dudar es de su honestidad como persona y como historiador. Este es un tema recurrente propio de intelectuales comprometidos con su tiempo y que escriben sobre él. Por ello, me ratifico en lo que expresé años atrás sobre su enfoque histórico:

Este particular enfoque histórico, centrado en la búsqueda de puntos de encuentro y en una matización de los puntos de vista en conflicto, no sólo es expresión de su formación católica jesuita que, como señalamos, se forjó dentro del contexto de las décadas de los sesenta y setenta, caracterizado por las corrientes progresistas dentro de la Iglesia, sino también de su propia personalidad: afable, dialogante, honesta. Klaiber fue un sacerdote tolerante, crítico y con una fe sincera (Portocarrero Grados, 2015, p. 138).

Recibido: 10 de enero de 2020

Aprobado: 15 de marzo de 2020

\section{Referencias bibliográficas}

\section{Libros de Jeffrey Klaiber S. J.}

The Role of the Gonzalez Prada Popular Universities in the Development and Formation of the Peruvian Aprista Movement. (Master of Arts dissertation). Chicago: Loyola University of Chicago. Actualmente hay una versión digital en: https://core.ac.uk/download/ pdf/48602896.pdf

(1976) Religion and Reform in Peru, 1824-1945. (Ph. D. dissertation). Washington: Catholic University of America. 
(1977) Religion and Revolution in Peru, 1824-1976. Notre Dame, Indiana: University of Notre Dame Press.

(1980) Religión y revolución en el Perú, 1824-1976. Lima: Universidad del Pacífico.

(1987) Klaiber, Jeffrey, coord. Violencia y crisis de valores en el Perú: trabajo interdisciplinario Lima: PUCP, Departamento de Humanidades.

(1988a) La Iglesia en el Perú. Su historia social desde la independencia. Lima: Fondo Editorial PUCP.

(1988b) Religión y revolución en el Perú, 1824-1988. 2.a ed. Lima: Centro de Investigación (CIUP), Universidad del Pacífico.

(1992) The Catholic Church in Peru, 1821-1985: a social history. Washington: Catholic University of America Press.

(1996) La Iglesia en el Perú. Su historia social desde la independencia. 3.a ed. Lima: Fondo Editorial PUCP.

\section{Artículos de Jeffrey Klaiber S. J.}

(1971) The Non-Communist Left in Latin America. Journal of the History of Ideas, 607-616.

(1975a) Religion and Revolution in Peru: 1920-1945. The Americas, 31 (3), 289-312.

(1975b) The Popular Universities and the origins of Aprismo, 1921-1924. Hispanic American Historical Review, 55 (4), 693-715.

(1978) El Apra: religión y legitimidad popular, 1923-1945. Apuntes (8), 49-58.

(1979) Las Universidades Populares y los orígenes del Aprismo, 1921-1924. Claridad: Tribuna de la Juventud Libre, 2 (6), 39-52.

(1997) Haya de la Torre: su teoría del espacio-tiempo histórico. En: H. Córdova (Ed.), Espacio: teoría y praxis 
(pp. 325-335). Lima: PUCP.

(2004) Enfoque histórico sobre Haya de la Torre. Tipshe: Revista de Humanidades, 4 (4), 237-244.

(2005) El miedo al APRA. En C. Rosas Lauro (Ed.). El miedo en el Perú: siglos XVI al XX (pp. 257-264). Lima: Fondo Editorial PUCP.

\section{Reseñas sobre Jeffrey Klaiber S. J.}

(1978) Reseña de Davies, Thomas M. Jeffrey L. Klaiber. Religion and Revolution in Peru, 1824-1976. (International Studies of the Committee on International Relations). Notre Dame, Ind.: University of Notre Dame Press. 1977. The American Historical Review 83 (3), 849-850.

(1978) Reseña de Klarén, Peter. Histórica 2 (1), 116-117.

(1978) Reseña de Klarén, Peter. The Americas, 35 (2), 276277.

(1978) Reseña de McFarland, Floyd B. Annals of the American Academy of Political and Social Science, 437, 156157.

(1979) Reseña de Epstein, Edward C, The Hispanic American Historical Review, 59 (1), 162-163.

(1979) Reseña de Gagliano, Joseph A. The Catholic Historical Review, 65 (2), 292-293.

(1980) Reseña de Mabry, Donald J. Religion and Revolution in Peru, 1824-1976. By Jeffrey L. Klaiber S.J. International Studies of the Committee on International Relations. Notre Dame and London: University of Notre Dame Press, 1977. Journal of Church and State 22 (2), 351-352.

(1980) Reseña de Nieto, Armando, S. J. Klaiber S, J., Jeffrey L. Religión y Revolución en el Perú, 1824-1976, Universidad del Pacífico, Departamento de Humanidades, Lima, 1980. Histórica 4 (1), 117-118. 
(1980) Reseña de Vega-Centeno, Imelda. Socialismo y Participación, (11), 279-283.

(1987) Reseña de Parker, David. Klaiber, Jeffrey, Religión y Revolución en el Perú, 1824-1988, 2.a ed. Apuntes: Revista de Ciencias Sociales, (21), 107-110.

\section{Bibliografía}

GUTIÉRREZ, Gustavo

(1971) Teología de la liberación: Perspectivas. Lima, Centro de Estudios y Publicaciones (CEP).

HAYA DE LA TORRE, Víctor Raúl

(1928-1936) El antiimperialismo y el Apra. Santiago de Chile: Ercilla.

HAYA DE LA TORRE, Víctor Raúl

(1963) El discurso programa de 1931. El aprismo en su línea. Lima.

HAYA DE LA TORRE, Víctor Raúl

(1955) Treinta años de aprismo. México: Fondo de Cultura Económica.

HOBSBAWM, Eric

(2018) "América Latina: no hay región más revolucionaria”, En Hobsbawm, Eric: ¡Viva la revolución! Sobre América Latina. (p. 53-60). Leslie Bethell, ed. Barcelona: Crítica.

MARIÁTEGUI LA CHIRA, José Carlos

(1928) 7 ensayos de interpretación de la realidad peruana. Lima: Biblioteca "Amauta".

PORTOCARRERO Grados, R. F.

(2015) Obituary: Jeffrey Klaiber, S.J. (1943-2014). Hispanic American Historical Review, 95 (1), 135-139.

ROSAS LAURO, C. (Ed.)

(2005) El miedo en el Perú: siglos XVI al XX (pp. 257-264). Lima: Fondo Editorial PUCP. 